
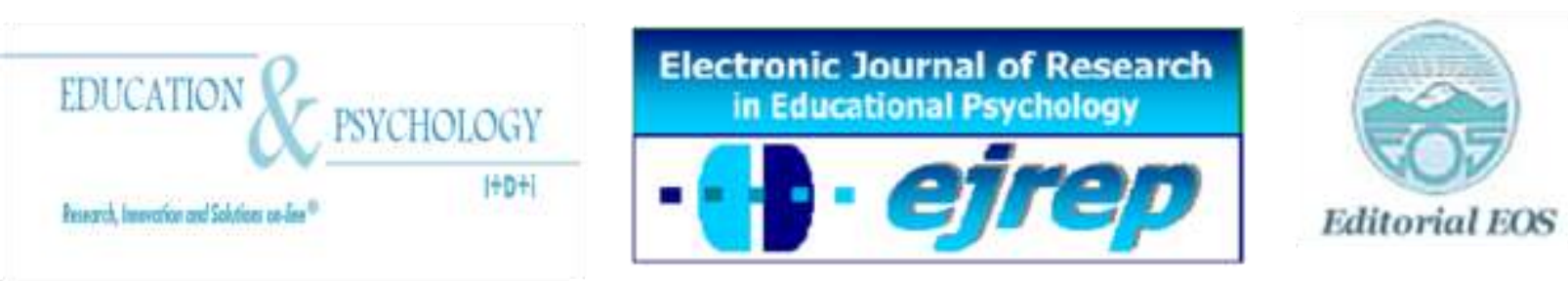

\title{
A qualitative approach of modelling activities for the notion of energy
}

\section{Olga Megalakaki ${ }^{1}$ and Andrée Tiberghien ${ }^{2}$}

${ }^{1}$ Faculté de Philosophie, Sciences Humaines et Sociales, Université de Picardie, Équipe CLEA, France.

${ }^{2}$ Université Lumière Lyon 2, UMR ICAR Équipe ADIS-COAST, France.

\section{France}

Correspondence: Olga Megalakaki, Université de Picardie, Faculté de Philosophie, Sciences Humaines et Sociales, Équipe CLEA, Chemin du Thil, 80025 Amiens Cedex 1, France. E-mail: olga.megalakaki@u-picardie.fr (C) Education \& Psychology I+D+i and Editorial EOS (Spain) 


\section{Abstract}

Introduction. Adopting a conceptual change perspective yields information not only about the organization of students' conceptions and the mechanisms behind their changes, but also about the most effective teaching interventions for promoting conceptual change. In experimental science, modelling constitutes a basic activity for acquiring and using scientific concepts, and a key method for eliciting conceptual change. The aim of this study was to investigate how modelling activities can elicit conceptual changes concerning the notion of energy.

Method. 40 students aged 16-17 years, working in pairs had to construct symbolic representations of three materially present experiments (Battery-bulb, Falling object and Rising object) drawing on a simple model that introduced them to the properties of energy. In order to track changes in their cognitive processes, we defined a number of specific modelling categories.

Results. Results showed that students implemented increasingly complex cognitive processes to solve the three problems. Modelling activities enhance the ability to process the material world and the world of theories and models simultaneously, even when there is no isomorphism between the two.

Discussion. The modelling activities we administered to students promoted efficient learning, insofar as the conceptual change mechanism was put in place. Solving the three problems allowed students to draw on their prior knowledge but also to develop new knowledge about the material and theoretical worlds. They acquired the ability to process representations simultaneously from concrete and conceptual worlds and to move freely between them, despite their lack of isomorphism.

Keywords: modelling activities, energy, cognitive processes, conceptual change. 


\section{Enfoque cualitativo de actividades de modelado para la noción de energía \\ Resumen}

Introducción. La adopción de una perspectiva de cambio conceptual no solo proporciona información acerca de la organización de las concepciones de los estudiantes y los mecanismos que hay detrás de sus cambios, sino también de las intervenciones más eficaces en la enseñanza para promover el cambio conceptual. En ciencias experimentales la modelización constituye una actividad fundamental para aprehender y utilizar conceptos científicos, y un método clave para motivar el cambio conceptual. El objetivo de este estudio fue investigar cómo las actividades de modelización pueden producir cambios conceptuales respecto a la noción de energía.

Método. Un toatla de 40 estudiantes, de 16 y 17 años, trabajando en parejas, han tenido que construir representaciones simbólicas de tres experimentos de física (batería-bombilla, caída de objeto y elevación de objeto), recurriendo a un modelo simple mediante el cual se introdujeron las propiedades de la energía. Con el fin de seguir los cambios en sus procesos cognitivos, hemos definido una serie de categorías específicas de modelización.

Resultados. Los resultados mostraron que los estudiantes utilizan procesos cognitivos cada vez más complejos para resolver los tres problemas. Las actividades de modelización mejoran la capacidad para procesar el mundo físico y el mundo de las teorías al mismo tiempo, incluso cuando no hay un isomorfismo entre ambos.

Discusión. Las actividades de modelización que se les administró a los alumnos promovieron un aprendizaje eficiente, ya que el mecanismo de cambio conceptual se puso en marcha. $\mathrm{Re}$ solver los tres problemas no sólo les permitió aprovechar sus conocimientos previos, sino también desarrollar nuevos conocimientos sobre el mundo físico y el mundo teórico. Los estudiantes adquirieron la capacidad para procesar representaciones de lo concreto y lo conceptual al mismo tiempo, así como para moverse libremente entre ambas.

Palabras clave: actividades de modelización, energía, procesos cognitivos, cambios conceptuales. 


\section{Introduction}

The way in which secondary school students learn scientific concepts is of interest both to cognitive psychologists and to science education researchers. Adopting a conceptual change perspective yields information not only about the organization of students' conceptions and the mechanisms behind their changes, but also about the most effective teaching interventions for promoting conceptual change. Studies conducted from this perspective underscore the importance of taking students' cognitive functioning into account in science education. By the time they are exposed to formal teaching, children have already constructed their own conceptions for a broad range of phenomena that occur in the world around them. These early ideas generally referred to as "intuitive" or "naive conceptions", are often erroneous and extremely robust, thus constituting obstacles to the acquisition of scientific knowledge. However, because of their crucial role in acquisition, it is important both to study them and to factor them into teaching.

Concerning energy, many naive conceptions are based on shared social interpretations (Solomon, 1992). According to the first of these, energy is an immaterial agency ("energy is a state of mind - it's how you feel"). The second interpretation is based on the connection between energy and life, in the sense that energy is identified as the activity of all living things. The third one concerns the relation of energy to work and power, insofar as it is a quantity that can be measured in terms of work. Students often think of energy as a mobile, polymorphous substance that can be stored and conserved (Duit 1987). When electric current is involved, students often regard the battery or generator as a reservoir of either energy or electricity, without really differentiating between the two (Shipstone 1988). Energy is also regarded as a form of causality - an agent that has a variety of effects, including heat, work and radiation. In physics lessons, teachers often introduce the notion of energy via this idea of causality, defining it as "the capacity for doing work". For their part, researchers investigating teaching about energy from a linguistic angle have analyzed the use of terms such as "energy forms", in order to identify possible incompatibilities (Kaper \& Goedhart, 2002). Collet (2000), for instance, showed that, in French, the use of the noun "transformation" and verb "transformer" requires the speaker to specify both the initial and final states of the transformation. 
In recent years, a number of different approaches have been developed with a view to exploring the status of naive conceptions and finding out how conceptual changes are achieved. These approaches differ both on the organization of naive conceptions and on the nature of conceptual change. For some authors, naive conceptions are organized (Carey 1985; Chi, Slotta \& de Leeuw 1994; Vosniadou \& Brewer 1994), while for others they are inconsistent (diSessa 1993, 2000). Similarly, while some regard conceptual change as sudden, others view it as a gradual process. According to Vosniadou and Brewer (1994) and Vosniadou (2002), as soon as children start engaging in cognitive activity, concepts are incorporated into relatively broad theoretical structures that encompass both specific theories and ontological and epistemological presuppositions. Conceptual change is described by these authors as a gradual process, whereby individuals move from initial models to scientific ones. Chi and Roscœ (2002), Chi et al. (1994) see conceptual change as the repairing of erroneous ideas. The latter take the form of incorrect categorizations of concepts, and conceptual change therefore involves reclassifying concepts in order to correct these categories. The authors describe conceptual change as a change of ontological category, asserting that all the entities making up our environment can be placed in separate ontological categories such as "matter", "process" and "mental states". Each time a new concept is learned, the learner associates it with one of these categories. This helps him or her understand the type of concept they are dealing with and any attributes it may have. Misconceptions occur when the learner associates the new concept with the wrong category. For example, in physics, pupils often place entities that physicists regard as belonging to the "process" category in the "matter" category. According to diSessa $(1993,2000)$, naive conceptions are made up of simple elements called "phenomenological primitives", or "p-prims", which represent superficial interpretations of physical reality that are constructed by learners in order to account for physical phenomena. These assemblages of p-prims cannot be said to constitute a coherent and systematic theory, and for diSessa, conceptual change consists either in reorganizing these p-prims or in organizing them in a more coherent and systematic fashion. As to the manner in which conceptual change takes place, we share Mayer's view that "conceptual change is a gradual process of knowledge construction" (Mayer 2002, p.109), the main challenge being to pinpoint the underlying mechanisms (De la Fuente, 2004; Gutiérrez Romero, 2004; Torrano, 2004). Our study sought to meet this challenge by attempting to describe the cognitive processes implemented by students in relation to the notion of energy. To this end, we devised a teaching intervention based on a modelling activity. Students were asked to construct symbolic representations of three 
materially present experiments, drawing on a simple model that introduced them to the properties of energy.

In experimental science, modelling constitutes a basic activity for acquiring and using scientific concepts, and a key method for eliciting conceptual change (Nersessian, 1999). According to Jonassen (2004) modelling helps learners to externalize their reasoning, and to visualize and test the components of their theories. As a model is a conceptual representation of a real system that obeys the laws of physics, building models helps learners to focus on the conceptual reconstruction of reality and to construct a coherent view of science (Hestenes 1987). The models described in the literature are many and various, and depend on the nature of the stated objectives. Giere (1999) makes a distinction between representative models, abstract models, hypotheses and theoretical models (abstract models built from theoretical principles). Harris (1999) identifies three types of models: theoretical models (abstract representations) experimental models (more specific models, designed to test the theoretical ones) and data models (data sets manipulated by scientists). Lehrer and Schauble (2003) also describe a number of models, including physical ones, representative systems (based on the model's resemblance to the real world), syntactic models (describing how the system works) and hypothetical-deductive models (formal abstractions).

In physics, the purpose of modelling is to predict how physical systems will perform. "Artificial worlds" are created in order to afford a glimpse of how the real world works and to predict what it may do (Ogborn 1998). Whatever the case, models must be qualitatively, functionally or formally similar to the real objects that are being studied (Yu 2002). Researchers working in this area have developed teaching materials featuring models and external representations (Chomat, Meheut \& Larcher, 1992; Durey, 1987; Lemeignan \& WeilBarais,1992 ; Tiberghien, 1994, Tiberghien \& Megalakaki, 1995; Megalakaki \& Tiberghien, 1995). Several studies have been based on epistemology (Bachelard 1979), with different types of models and modelling tasks being devised (Gilbert \& Boulter, 1998; Linn \& Muilenberg, 1996; Perkins, 1986) in order to ascertain whether students are indeed capable of carrying out modelling activities and whether these activities are conducive to learning physics (Bécu-Robinault 1997). Gilbert and Boulter (1998) have suggested that, in science, models help students make predictions, guide their investigations, summarize data, justify results and make communication easier. The approach developed by Tiberghien (1994) and adopted in the present study draws together the threads of epistemology, psychology and science educa- 
tion. According to Tiberghien, students learning physics find it particularly difficult to establish relations between the material world of objects and events and the world of theories and models, due to the fact that there is no isomorphism between the two. The concept of energy, for instance, has no physical counterpart. This difficulty has been confirmed in epistemological research. Giere (1988)'s study, for instance, undertaken from a cognitive perspective, confirmed the complexity of the articulation between the material and theoretical worlds.

Other researchers have carried out fine-grained analyses of cognitive processes in order to find out why they lead to different results in different individuals (Chin \& Brown 2000). To analyze their data, these authors devised a number of categories to show how pupils conceive of "objects, events and phenomena, and various aspects of scientific discourse such as hypotheses, predictions, observations, explanations, questions, evidence, arguments, models and theories" (p.118). When Aufschnaiter and Welzel (1999) investigated changes in learning processes, they found that the complexity of students' ideas increases in the course of task resolution (in terms of objects, properties, events, etc.).

\section{The present study}

In the light of previous findings on naive conceptions, conceptual change and modelling (Giere 1988; Tiberghien 1994), highlighting the difficulty that physics students have establishing relations between the material and theoretical worlds, we sought to find out how modelling activities can promote the process of conceptual change concerning the energy concept. Students had to construct symbolic representations, or "energy chains" (see Appendix 1), of three materially present experiments, drawing on a simple model that introduced them to the properties of electricity. They solved the three successive modelling problems by establishing relations between objects and events in the material world (e.g., battery, bulb, electricity) and the elements of a formal energy model (energy reservoir, transformer and transfer).

Our selection of problems that would promote conceptual change was guided by the model of cognitive conflict as it is supposed that students will be presented a problem or a situation in which their prior knowledge does not work and it cannot predict a valid solution. (Limon, 2001; Posner, Strike, Hewson \& Gertzog, 1982;). In this sense, the "battery-bulb" problem we administered first was therefore particularly appropriate, as it is elicits the activa- 
tion of prior knowledge and a conflict between prior and new knowledge. We hypothesised that, in order to solve the problem, students would construct a representation of the notion of energy by activating their prior knowledge of electric current (taught in a previous year). This would allow us to examine the process of conceptual change (shift from the electric current perspective to an energy model perspective) in real time. The students were unfamiliar with the second and third problems. The main difficulty posed by the second one ("falling object") stemmed from the need to associate the falling object with the initial reservoir. In order to match the two correctly, they had to stop regarding the object as an object and concentrate instead on its behaviour (i.e., falling). Similarly, in the third problem ("rising object"), in order to match the rising object with the final reservoir, students had to consider the object's state or behaviour (i.e., rising or high).

In order to solve the problems, we expected the students to draw on their prior knowledge (acquired either at school or in the course of their daily lives), taking the elements of the energy model into account. We focused our analysis on the cognitive processes they engaged to move freely between the material and conceptual components. To pinpoint changes in the complexity of these processes, we broke them down into a number of categories specific to modelling (see Table 1). These categories ranged from basic one-to-one "matching" to "similarity of structure", whereby sets of elements from each world are linked together and given a shared interpretation.

Research on the formal modelling of these three problems (Bental, Tiberghien, Baker \& Megalakaki, 1995) has shown that they can be solved using simple "matching" and "similarity of behaviour" processes. However, given that modelling activities enhance the ability to juggle several different elements, we predicted that the complexity of the cognitive processes would change in the course of the three problems, thereby favouring the ability to process (1) material components (e.g., objects or events linked to the experiment, (2) conceptual elements (e.g., text of the theoretical model of energy) and (3) their interpretation (e.g., the energy chain diagram) simultaneously.

It is important to highlight the overlap between everyday knowledge and the knowledge required by the modelling activities performed by the students. For example, "reservoir" and "transformer" are concepts that refer to physical objects, and we therefore expected this to make it easier to draw links between theory and reality. "Transfer" (e.g., energy transfer), on 
the other hand, is immaterial and does not have any obvious physical counterpart. We therefore postulated that learners would find it harder to construct its meaning. Possible changes in the meaning of the notion of energy transfer across the three problems were a secondary focus of our study.

\section{Method}

\section{Participants}

Our sample comprised 40 students (20 girls and 20 boys) aged 16-17 years (mean age 16.7, SD: 4 months) working in pairs. They were drawn from two secondary schools in the cities of Lyon and Amiens.

\section{Tasks and instruments}

Students had to produce three symbolic representations of an energy chain corresponding to three materially present experiments (see Fig. 1 for the problems and the expert solutions), using information contained in an elementary theoretical model of energy that listed two internal rules which had to be followed and identified elements of the energy chain (Appendix 1). These elements included a reservoir (represented by a rectangle), a transformer (represented by an oval) and an energy transfer (represented by arrows). Students were given the following instruction: "Use this energy model to draw the energy chain corresponding to the experiment". The three successive experiments were:

Battery-bulb. A battery is connected by two wires to a bulb that lights up (Fig. 1). The difficulty of this problem lay in the fact that the experiment was familiar to students and might therefore favour the activation of prior knowledge about electric current.

Falling object. An object is suspended from a string, which is initially wound around the shaft of a motor (like a dynamo). A bulb is connected to the motor. When the object is released and falls, the bulb lights up (Fig. 1). This problem was difficult for two reasons. First, in order to match the falling object with a reservoir, students had to consider not the object itself but its behaviour (i.e., falling). Second, two successive objects (motor and lamp) had to be associated with a transformer.

Rising object. A battery is connected to an electric motor. A string is attached to the motor shaft and an object is suspended from this string. When the motor's circuit is closed, the string 
is wound around the shaft and the object rises (Fig. 1). In this problem, it was the modelling of the final reservoir and its linking with the rising object that presented the main difficulty. Once again, students had to match the reservoir with the behaviour (rising) or condition (high) of the object.
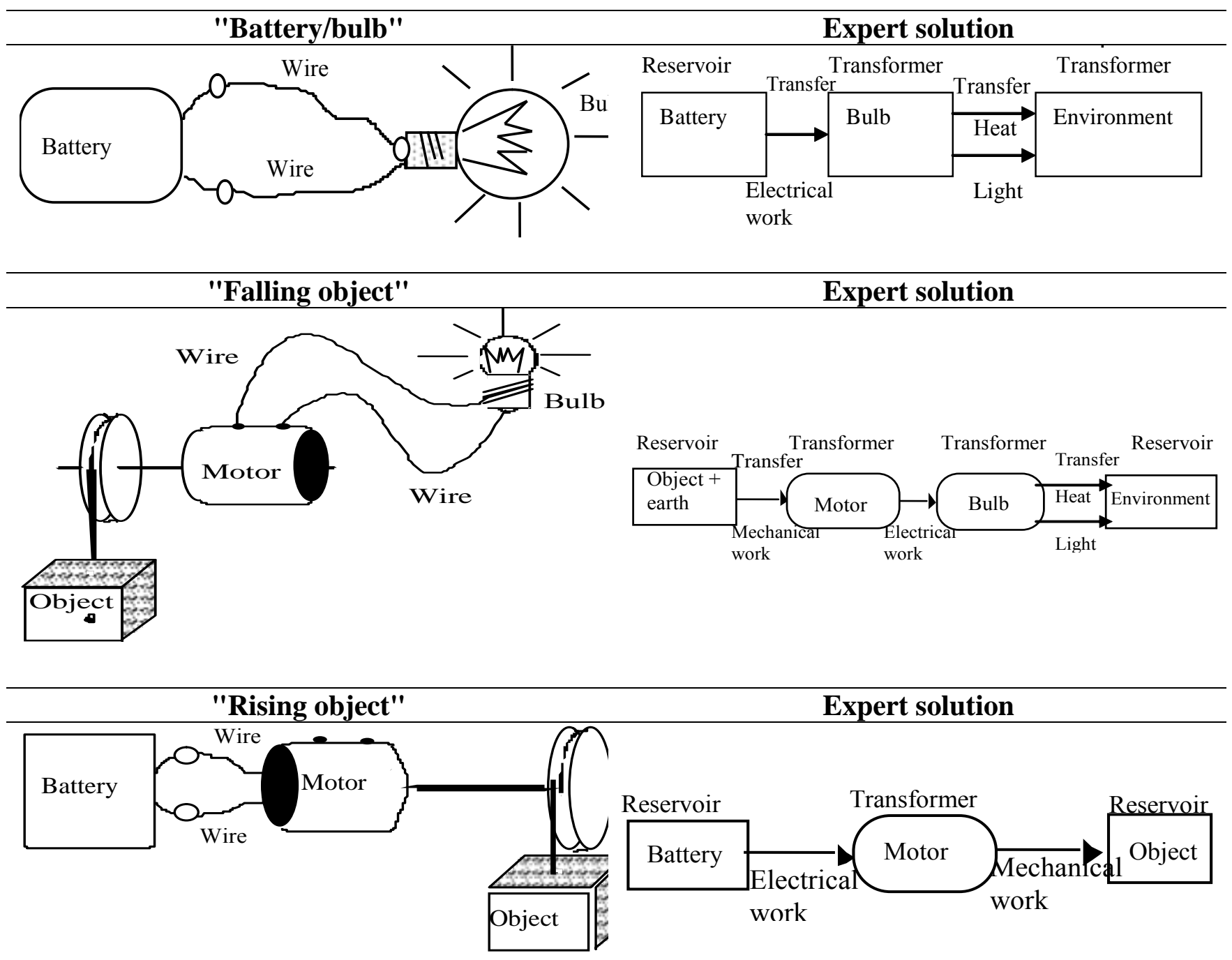

Figure 1. "Battery/bulb","Falling object" and"Rising object" experiments and expert solutions

\section{Procedure}

We conducted our study in the wake of teaching sequences on the laws and principles of energy prescribed by the French national curriculum. In the experimental phase, each pair had to come up with a shared solution for each problem (construction of an energy chain). 
This phase lasted 90 minutes and students were instructed to "use this energy model to draw the energy chain corresponding to the experiment". The teacher explained the procedure and encouraged the students to work together to produce a solution, using paper and pencil. The three problems were administered to all the students in the same order. The experimental phase took place over four sessions: during each session, five pairs solved the problems in the same room.

\section{Categories for analyzing the modelling activities}

Our analysis of the data allowed us to construct categories in order to analyse modelling activities according to the types of actions performed by the students (Table 1).

Table 1. Categories for analyzing the modelling activities (i.e., establishment of correspondences between theoretical and material worlds)

\begin{tabular}{|c|c|c|}
\hline Categories & Description & Example \\
\hline Matching & $\begin{array}{l}\text { Corresponds to the explicit associa- } \\
\text { tion between one element of the } \\
\text { material world and one element of } \\
\text { the theoretical model }\end{array}$ & Battery/bulb: "the battery is a reservoir" \\
\hline $\begin{array}{l}\text { Similarity of be- } \\
\text { haviour }\end{array}$ & $\begin{array}{l}\text { Elements of each world display } \\
\text { similar behaviour }\end{array}$ & $\begin{array}{l}\text { Battery/bulb: "the reservoir stores en- } \\
\text { ergy, in the battery there's energy" }\end{array}$ \\
\hline $\begin{array}{l}\text { Application of } \\
\text { rules/definitions sup- } \\
\text { plied by model }\end{array}$ & $\begin{array}{l}\text { A rule or a definition is used explic- } \\
\text { itly to establish relations between the } \\
\text { two worlds }\end{array}$ & $\begin{array}{l}\text { Battery/bulb: "the reservoir stores energy, } \\
\text { so the battery is a reservoir" }\end{array}$ \\
\hline Adaptation & $\begin{array}{l}\text { Establishing a relation between the } \\
\text { theoretical model and the material } \\
\text { world needs further development of } \\
\text { either the model or the description of } \\
\text { the experimental situation }\end{array}$ & $\begin{array}{l}\text { Falling object: "the weight is in fact a } \\
\text { reaction. Simply to show that the motor } \\
\text { is running...." }\end{array}$ \\
\hline $\begin{array}{l}\text { Intermediate interpre- } \\
\text { tation }\end{array}$ & $\begin{array}{l}\text { When events in the model or the } \\
\text { material world are interpreted }\end{array}$ & $\begin{array}{l}\text { Falling object: "the object is the reser- } \\
\text { voir, it falls and this produces energy..." }\end{array}$ \\
\hline Predictive reasoning & $\begin{array}{l}\text { This reasoning predicts an event in } \\
\text { the material world by taking the } \\
\text { theoretical model as its starting } \\
\text { point, and vice-versa }\end{array}$ & $\begin{array}{l}\text { Battery-bulb: "this arrow means that the } \\
\text { energy goes from the transformer to the } \\
\text { reservoir. This is unheard of and would } \\
\text { mean the bulb never went out" }\end{array}$ \\
\hline Similarity of structure & $\begin{array}{l}\text { Two or more elements belonging to } \\
\text { one world are explicitly related to } \\
\text { one or more elements belonging to } \\
\text { the other world }\end{array}$ & $\begin{array}{l}\text { Falling object: "the weight yields a sort } \\
\text { of energy, a force, which goes into the } \\
\text { motor and the motor produces energy, so } \\
\text { it's a transformer; it turns force into en- } \\
\text { ergy" }\end{array}$ \\
\hline
\end{tabular}


Data collection, coding and statistical analysis

We collected the sheets on which the students had drawn the energy chains. Audio recordings of the students solving the problems were transcribed and supplemented with information from video recordings. In these scripts, each student's intervention was numbered so that the data could be analyzed in accordance with our categories (see Appendix 2 for an excerpt of a dialogue between students and an example of our category-based data coding).

For coding purposes, one or several utterances could correspond to a single category (see example in Appendix 2). We counted the number of times each category featured in the students' dialogues. For example, if the students matched the battery with the reservoir in ref. 10 and reiterated this matching in ref. 30, we counted two occurrences. This is because the problem-solving process often includes self-questioning, look backs and reassertions. Our data were coded by two independent examiners and interrater agreement was $91 \%$. All disagreements were discussed and resolved. For the statistical analysis, we conducted a nonparametric two-way analysis of variance of Friedman $\left(\mathrm{X}_{\mathrm{r}}^{2}\right)$ to assess changes in the students' cognitive processes.

\section{Results}

\section{Students' energy chains}

Students produced several different types of solution. Table 2 provides an overview of the specific difficulties presented by each of the three problems. For the first problem (batterybulb), 13 pairs produced a closed chain, corresponding to the model of the closed electric circuit, four pairs produced the correct chain, two came up with a chain that had the right structure but the wrong terms and one pair constructed a chain that we were unable to place in any of the foregoing categories. The second problem (falling object) was remarkable for the fact that two consecutive objects (motor and bulb) were both transformers. Once again, we counted three different types of solution: correct solutions (11 pairs), chains with three elements (five pairs) and chains with the right structure but the wrong terms (four pairs). For the third problem (rising object) 14 pairs produced the correct chain and five produced chains where the final element - the most difficult one - was wrong. Once again, one pair constructed an unclassifiable chain. 
Table 2. Classification of students' solutions to the three problems

\begin{tabular}{lccc}
\hline & Battery-Bulb & Falling object & Rising object \\
\hline Solutions & \multicolumn{3}{c}{ Number of pairs } \\
\hline Correct chain & 4 & 11 & 14 \\
Closed chain: battery at both ends & 13 & & \\
Correct structure with incorrect terms & 2 & 4 & 5 \\
Chain with three elements & & 5 & 1 \\
Final object incorrect & 1 & & 20 \\
Other & 20 & 20 &
\end{tabular}

\section{Processes used to solve the three problems}

Battery-Bulb. Our analysis of the scripts for the battery-bulb problem showed that the students drew on their everyday knowledge to construct meanings for "reservoir" and "transformer". Almost all the students established correct relations between the battery and reservoir and the bulb and transformer, reflecting the simple "matching" and "similarity of behaviour" processes (see Table 3 for a breakdown of how this problem was solved and Table 4 for the frequency of occurrence of each cognitive process). The students began by linking up the battery and the reservoir on the basis of their common storage property ("the reservoir stores energy, so it must be the battery"). In order to associate the transformer with the bulb, the students ascribed the shared property of "transformation" of input into output to them both. This association was less obvious for some students than the one between the reservoir and the battery, as they had to state explicitly that it was the bulb that was doing the transforming. For example, in the L-D pair, student L was not initially convinced by student D's suggestion that the bulb should be treated as a transformer ("does the bulb transform something?"), although a few minutes later he agreed with the statement that "the transformer transforms energy, [...] and, well, the bulb turns energy into light, OK?".

Unlike "reservoir" and "transformer", "transfer" proved a very difficult concept for students to grasp and one that remained particularly poorly understood. Most of them began by associating it with a material object (i.e., wires). They then tried to dissociate it from the ma- 
terial world by making "elaborations" ("that's how energy is transferred" or "it's a sort/ a model a system").

The hardest part of this problem was modelling the whole experiment by constructing the energy chain. In accordance with the law of conservation of energy, a physicist would take the environment to be the appropriate system, with the energy from the "battery" reservoir and the light/heat from the "bulb" transformer going into the environment. However, all the pairs came up with closed energy chains resembling electric circuits (Table 3), at least to begin with. In order to produce their chains, they activated their prior knowledge about how a closed circuit works and used the "similarity of structure" process to establish correspondences between the energy and electricity models, drawing two arrows to indicate two-way transfers (Table 4). To justify these correspondences, they also carried out "adaptations" ("it's circular and that's what happens here - you can see how it leaves a reservoir and then comes back to a reservoir" or "the wire going back to the battery isn't a transfer, it's just there to close the circuit so that the energy can circulate"). This outcome triggered a cognitive conflict for four pairs, who proceeded to take a second look at the closed chains they had produced and restructured their knowledge in a bid to resolve this conflict. Their selfquestioning was accompanied by "predictive reasoning" ("that arrow [transfer] means that the energy flows from the transformer to the reservoir, but that's unheard of, because it would mean that the bulb never went out and we all know that's not possible..."). All the other pairs produced a solution featuring an incorrect closed chain.

Table 3. Solution of the battery-bulb problem.

\begin{tabular}{lc}
\hline \multicolumn{2}{c}{ BATTERY-BULB } \\
\hline \multicolumn{2}{c}{ Number of pairs } \\
\hline Initial production of a closed chain & 20 \\
Transfer direction vice-versa & 20 \\
Questioning the closed aspect of the chain & 16 \\
Reservoir-battery: storage & 17 \\
Transformer-bulb : transformation & 20 \\
Transfer corresponds to an object & 18 \\
\hline
\end{tabular}

Falling object. The first hurdle here was to establish the correspondence between the first reservoir and the falling object. Students had to take into account not the object itself but its behaviour: the fact that it fell from a height. Students who clung to the notion of storage in its 
narrower sense were unable to find an appropriate initial reservoir. One student, for instance, said "a reservoir stores energy, but weight doesn't store energy". Most students, however, overcame this difficulty by eschewing "matching" in favour of more complex cognitive processes, such as "adaptation" and "similarity of structure". To perform adaptations, students took the action associated with the object as their starting point ("it's the object's weight that makes/produces/ gives..." or "weight doesn't store energy but it does produce it... in that it falls... like when you throw"). Although the subject of the verb "produce" is the object's weight in these examples, it could equally well have been the reservoir, even though this particular action verb did not figure in the model. This type of adaptation therefore required students to process a role or property of an object in the experiment (falling object) alongside a property of one of the elements in the model (storage). After they had performed these adaptations, some of the pairs went on to match the object with the reservoir.

A further difficulty arose from the fact that two successive objects, namely the motor and the bulb, had to be associated with a transformer. In order to overcome this difficulty, some of the students undertook "similarity of structure" processes, establishing correspondences between sets of elements belonging to the real and theoretical worlds ("weight gives a sort of energy, a force, which goes into the motor and the motor produces energy, so... it's a transformer. It transforms force into energy"). In the dialogue excerpt in Appendix 2, where student S (ref. 154) prompts student $M$ to clarify his suggestion (ref. 157), each of the two students structures the experiment differently, using "intermediate interpretations". S concentrates on storage, while $\mathrm{M}$ implements the more complex "similarity of structure" process. $\mathrm{M}$ adapts his interpretation using action verbs such as "fill" and "charge" for the battery. Instead of simply helping himself to the knowledge that is available to him, he constructs and processes new items of knowledge. This excerpt is a good illustration of the difference in conceptual construction between basic "matching" and a "similarity of structure" process involving other processes such as "intermediate interpretation". In "similarity of structure", students establish not one but several links between the concepts and enrich these concepts with new properties. We believe that more complex processes lead to more efficient learning.

The third and final difficulty, which persisted even after the previous problem has been solved, concerned "transfer" and its irrelevant associations with a real-life object ("motortransfer" or "transfer-falling object"). Initial instances of matching were followed by "elaborations" ("it's not an object, it's a way, for example, a ray, and rays aren't motors. The motor is 
a transformer"). The students then engaged in a form of meta-resolution, using the terms provided by the model and referring to the didactic contract ("we have to use the terms given in the model").

Rising object. The students had no difficulty modelling the first two objects (battery and motor) in this problem, as relations with the theoretical components had already been established in the previous two problems. The main obstacle, therefore, was posed by the modelling required to associate the final reservoir with the "rising object", concentrating on the latter's behaviour (rising) or state (high). The scripts showed that the students undertook "adaptations" in a bid to solve the problem ("lead is like the environment, it's a reservoir") and looked for "similarities of structure" ("create, reservoir, name battery... The motor will be the transformer. OK! ... Transfer. Work. But the object, that'll be the reservoir, then? No, it's not a reservoir. No, if it's not a reservoir it must be a transformer. No, we'd better put reservoir. Yes, we need a final reservoir..."). In these excerpts, correspondences are drawn between several material and theoretical elements. The students' arguments that eventually led them to the correct solution focused entirely on the model and explicitly referred to the need for a final reservoir to store the energy. These dialogues give us some idea of the complexity of the modelling here, where the model proved easier to process than the material world (even though apparent concreteness is supposed to be easier to deal with).

As for energy transfer, some students continued to associate it with physical objects ("switch", "mass", "shaft"). At the same time, we also observed the emergence of "adaptations" ("it's our work", "It's the result, not the work [between motor and weight]", "traction"). The students eventually made use of the information provided in the theoretical model text, referring to the different modes of energy transfer ("work", "heat", "radiation").

\section{Changes of the cognitive processes across the three problems}

An analysis $\mathrm{X}_{\mathrm{r}}^{2}$ Friedman of the modelling processes used by the students to solve the three problems revealed an significant effect, $\mathrm{X}_{\mathrm{r}}{ }_{\mathrm{r}}(2)=22,794 ; p=.0001$. Post hoc Bonferroni tests revealed an significant effect between the first and the third problem $(p=.0001)$ and between the second and third problem ( $\mathrm{p}=.001)$. To solve the first problem (battery-bulb), the students relied mainly on simple cognitive processes, such as "matching" and "similarity of behaviour", but in the course of the following two problems, these simple processes gave way 
to the more complex ones of "adaptation", "intermediate interpretation"' and "similarity of structure".

Table 4. Frequency of occurrence of cognitive processes used by students to solve the three tasks

\begin{tabular}{llll}
\cline { 2 - 4 } & Battery-Bulb & Falling-object & Rising-object \\
\hline Modelling processes & & & \\
1. Matching & $149(30 \%)$ & $91(23.9 \%)$ & $50(19.9 \%)$ \\
2. Similarity of behaviour & $87(18 \%)$ & $32(8.4 \%)$ & $17(6.7 \%)$ \\
3.Application of rules/ & & & \\
definitions supplied by model & $79(16.3 \%)$ & $67(17.6 \%)$ & $37(14.7 \%)$ \\
4. Adaptation & $38(7.8 \%)$ & $76(20 \%)$ & $39(15.5 \%)$ \\
5. Intermediate interpretation & $37(7.6 \%)$ & $57(15 \%)$ & $60(23.9 \%)$ \\
6. Predictive reasoning & $33(6.8 \%)$ & $14(3.6 \%)$ & $11(4.3 \%)$ \\
7. Similarity of structure & $24(4.9 \%)$ & $51(13.4 \%)$ & $45(17.9 \%)$ \\
TOTAL & 482 & 380 & 251 \\
\hline
\end{tabular}

\section{Discussion and Conclusion}

Our study showed that modelling activities promote the use of efficient cognitive strategies for bringing about conceptual change and acquiring new knowledge. As these activities prompted students to activate their prior knowledge, subsequent competition from the theoretical model generated conceptual conflicts, leading them to reconsider this knowledge. Posner et al. (1982) hold that this conflict situation, brought about by dissatisfaction with the existing concepts, constitutes the first phase in the process of conceptual change. It is this imbalance that impels students to change or reorganize existing concepts in order to resolve the conflict.

The results of the battery/bulb problem confirmed our prediction that students would activate prior knowledge about electric circuits and that this knowledge would be adapted to take account of the energy chain notion. We believe that this initial problem was particularly destabilizing, in that it triggered a major conflict between the students' prior and newlyacquired knowledge (Posner et al. 1982). From that point onwards, they readily performed adaptations and reorganizations in order to model the experiments in accordance with the theoretical model. In the process, they discovered similarities and differences between their prior knowledge and the information they had just been given. To process the terms reservoir and transformer, the students relied mainly on conceptions derived from their everyday ex- 
periences, as they had not yet been introduced to these terms at school. They associated the reservoir with the battery, ascribing the property of storage to them both, and the transformer with the bulb, attributing to them the shared property of transformation, as in Collet (2000). These correspondences were established chiefly by means of the simple "matching" and "similarity of behaviour" processes (one-to-one matching of a material object with a theoretical element on the basis of a shared property).

The case of the reservoir and transformer illustrates the ease with which new knowledge can be acquired when it does not compete with prior knowledge (Vosniadou \& Brewer 1994). The case of transfer, on the other hand, shows how difficult it is to take new information on board when it is so far removed from the student's prior knowledge. Here, students tried to adapt the new information they had been given to their existing notions, based on everyday knowledge and previously acquired knowledge of electricity. Thus, the closed energy chains they constructed in a bid to model the battery-bulb experiment corresponded to their prior knowledge of electricity, in particular the fact that an electric circuit is closed. As they had never been taught the difference between electricity and energy, their initial representations of the energy chain showed the energy flowing through it exactly as electricity flows through a circuit. These results confirmed our hypothesis on the activation of prior knowledge and the importance of this activation for elaborating new knowledge. When their prior knowledge came into conflict with the theoretical model of energy, students were forced to reconsider the chains they had constructed. In a metacognitive activity, they therefore replaced the closed energy chains with others that were closer to the energy model.

The case of energy transfer also illustrates the difficulty of undertaking conceptual change when it requires a change of ontological category (Chi \& Roscoe 2002). Energy transfer corresponds not to a physical object but to a process arising from an event, such as "it's getting hot" (energy), "it's moving" (work) or "there's radiation" (light). However, students initially associated it with an object from the material world (i.e., wire), placing it in the "matter" category when it actually belonged to the "process" one. Some students subsequently undertook a form of meta-resolution and came up with new definitions of transfer, by making adaptations, such as "positive-negative", "electric current" or "displacement of electric charge". 
The results of the other two problems also confirmed our hypothesis on the development of students' knowledge of both the material and theoretical worlds. As demonstrated by Aufschnaiter and Welzel (1999), problem solving encouraged the students to implement increasingly complex cognitive processes. The modelling activity allowed them to acquire knowledge not just about the material world, via the model, but also about the model itself, as both a "tool" for linking the two worlds and a coherent body of knowledge with a theoretical underpinning. In order to solve the second and third problems, the students implemented complex "similarity of structure" processes, establishing correspondences between sets of elements belonging to the material and theoretical worlds. Interestingly, in the second problem, these "similarity of structure" processes took the experiment as their starting point. For example, in order to associate the reservoir with the falling object, they began with the action associated with the object ("the object doesn't store energy, but it does produce it, when it falls, as if you were throwing "). The modelling activity therefore allowed the students to develop their knowledge of the material world via the model. As for the third problem, as we have seen, the main difficulty lay in establishing a correspondence between the final reservoir and the "rising object", which required students to consider the object's position. In order to overcome this difficulty, they again implemented complex cognitive processes, but taking the model as their starting point, rather than the material world. The examples we have given illustrate both the difficulty of modelling activities (Giere, 1988) and their usefulness, in that they force students to implement complex cognitive processes requiring a higher level of abstraction. Students were more successful in their handling of the energy transfer notion in both the second and third problems. Most of them applied the model's rules and associated energy transfer with a process. That said, some students persisted in flouting the rules till the very end and performed "adaptations". This highlights the difficulty of conceptual change when new knowledge competes with prior knowledge and requires a thoroughgoing modification of the initial conception and its relations with the other concepts (Vosniadou \& Brewer 1994). Furthermore, this result suggests that conceptual change is a gradual process of knowledge construction.

During the dynamic solution elaboration process, the students constructed new links between their knowledge of the material and theoretical worlds. Some of this knowledge was new to them (e.g., the text on the energy model), but other items of knowledge had already been acquired, either in the course of their daily lives or else at school (e.g., battery-bulb experiment). These new links could be forged by implementing either simple or complex cogni- 
tive processes. When the students used simple ones, such as "matching" and "similarity of behaviour", they connected a material element of the experiment with an abstract concept on the basis of a shared property. For example, the battery was matched with the reservoir because they shared the same storage property. We deemed these basic one-to-one correspondences to be of a static nature.

The more complex cognitive processes ("adaptation", "intermediate interpretation", "predictive reasoning" and "similarity of structure") required students to establish correspondences between entire sets of material and theoretical elements, and thus to engage in more elaborate reasoning. Here, the term "complexity" took on a dynamic meaning, in that all three components of the modelling activity had to be present, with students interpreting the functioning of each world in order to extract the invariants, establish appropriate relations and construct a shared representation. This involved activating the knowledge they had previously acquired in the classroom or in the course of their daily lives in order to interpret the new information and construct new representations. We believe that these complex cognitive processes result in more efficient conceptual learning, in that they require students simultaneously to process and interpret several elements from the material and theoretical worlds.

It is important to emphasise that the changes in the complexity of the cognitive processes were not entirely due to differences between the problems. Studies investigating the formal modelling of these very same problems (Bental et al. 1995) have shown that the second and third ones can be solved using the same processes as in the first one, namely "matching" and "similarity of behaviour". The increasing complexity of the correspondences, revealing the achievement of a deeper understanding of the material world via the conceptual one and vice-versa, is therefore proof of the contribution of the modelling activity to efficient learning.

The modelling activities we administered to students promoted efficient learning, insofar as the conceptual change mechanism was put in place. Solving the three problems allowed students to draw on their prior knowledge but also to develop new knowledge about the material and theoretical worlds. They acquired the ability to process representations simultaneously from concrete and conceptual worlds and to move freely between them, despite their lack of isomorphism. Given that we regard conceptual change as a gradual process and one that cannot be observed after a single teaching intervention, our findings have obvious limita- 
tions. However, one important result does emerge from this study, concerning the increasing complexity of the cognitive processes engaged by the students, namely that the students' initial recourse to prior knowledge, followed by their experience of conceptual conflict, spurred them to modify their existing knowledge and move to a higher conceptual level.

\section{References}

Aufschnaiter S., \& Welzel M. (1999). Individual Learning Processes. A Research Program with Focus on the Complexity of Situated Cognition, in M. Bandiera, S. Caravita, E. Torraca and M. Vicentini (Eds), Research In Science Education in Europe, (pp. 209-215). Dordrecht, Kluwer Academic Publisher.

Bachelard, S. (1979). Quelques aspects historiques des notions de modèle et de justification des modèles. In P. Delattre \& M. Thellier (Eds.), Elaboration et justification des modèles, Vol. 1 (pp. 3-19). Paris: Maloine S.A.

Bécu-Robinault, K., (1997). Rôle de l'expérience en classe de physique dans l'acquisition des connaissances sur les phénomènes énergétiques, Thèse de doctorat, Université Lyon I.

Bental, D., Tiberghien, A., Baker, M., \& Megalakaki, O. (1995). Analyse et modélisation de l'apprentissage des notions de l'énergie dans l'environnement “CHENE”. In D. Guin, J.F. Nicaud. D. Py (Eds) Environnements Interactifs d'Apprentissage avec Ordinateur, (pp. 137-148). Paris: Eurolles.

Carey, S. (1985). Conceptual change in childhood. Cambridge, MA: MIT Press/Bradford Books.

Chi, M. T. H., Slotta, J. D., \& de Leeuw, N. (1994). From things to processes: A theory of conceptual change for learning science concepts. Learning and Instruction, 4, 27-43.

Chi, M. T. H., \& Roscoe, R. D. (2002). The process and challenges of conceptual change. In M. Limon \& L. Mason (Eds.), "Reconsidering conceptual change: Issues in theory and practice" (pp. 3-27). Dordrecht: Kluwer.

Chin, C., \& Brown, D. E. (2000). Learning in science: a comparison of deep and surface approaches. Journal of Research in Science Teaching, 37, 109-138.

Chomat, A., Larcher, C. \& Meheut, M., (1992). Modèle particulaire et démarches de modélisation. In Martinand J.L Enseignement et l'apprentissage de la modélisation en sciences, (pp. 119-169). INRP.

Collet, G. (2000). Langage et modélisation scientifique. Paris: CNRS éditions. 
De la Fuente, J. (2004). Recent perspectives in the study of motivation: the Theory of Goal Orientation. Electronic Journal of Research in Educational Psychology, 2 (1), 35-62.

DiSessa, A. (1993). Towards an epistemology of physics. Cognition and Instruction, 10, 105225.

DiSessa, A. (2000). Changing minds. Cambridge, MA:MIT Press.

Duit, R. (1987). Should energy be introduced as something quasi-material? International Journal of Science Education, 9, 139-145.

Durey, A., (1987). Vers des activités didactiques de mise au point de modèle de physique avec des micro-ordinateurs. Exemples: trajectoires, frappes et rebonds de balles en rotation, Thèse d'état.

Giere, R.N. (1988). Explaining Science a cognitive Approach. Chicago: University Chicago press.

Giere, R.N. (1999). Using models to represent reality. In L. Magnani, N.J. Nersessian, \& P. Thagard (Eds.), Model-based reasoning in scientific discovery, (pp. 41-58). New York: Kluwer Academic/Plenum Publishers.

Gilbert, J. \& Boulter, C. (1998). Learning science through models and modeling. In B. Fraser and K. Tobin (Eds), International Handbook of Science Education, (pp. 52-66). Netherlands: Kluwer.

Gutiérrez-Romero, M.F (2004). Epistemological Understanding and Inductive Inference: A study of physics in Early Childhood Education, Electronic Journal of Research in Educational Psychology, 2(1), 63-80.

Harris, T (1999). A hierarchy of model and electron microscopy. In L. Magnani, N.J. Nersessian, \& P.Thagard (Eds.), Model-based reasoning in scientific discovery, (pp. 139-148). New York: Kluwer Academic/Plenum Publishers.

Hestenes, D. (1987). Towards a modeling theory of physics instruction. American Journal of Physics, 55, 440-454.

Jonassen, D.H. (2004). Model Building for Conceptual Change:Using Computers as Cognitive Tools, 4 Congres ETIE, October, University of Athens.

Kaper, W. H. \& Goedhart, M. J. (2002). Forms of Energy', an intermediary language on the road to thermodynamics? Part I. International Journal of Science Education, 24, 81-95.

Lehrer, R., \& Schauble, L. (2003). Origins and evolution of model-based reasoning in mathematics and science. In R. Lesh \& H.M. Doerr (Eds.), Beyond constructivism: Models and modeling perspectives on mathematics problem solving, teaching, and learning (pp. 59- 70). Mahwah, NJ: Lawrence Erlbaum Associates. 
Lemeignan, G. \& Weil-Barais, A. (1992). L'apprentissage de la modélisation dans l'enseignement de l'énergie. In Enseignement et apprentissage de la modélisation en sciences, INRP/ LIREST.

Limon, M. (2001). On the cognitive conflict as an instructional strategy for conceptual change: a critical appraisal. Learning and Instruction, 11, 357-380.

Linn, M.C. \& Muilenberg, L. (1996). Creating Lifelong Science Learners: What Models Form a Firm Foundation?. Educational Researcher, 25, 18-24.

Mayer, R.E., (2002). Understanding conceptual change: a commentary: In M. Limón and L. Mason (eds), Conceptual change reconsidered: issues in theory and practice, (pp. 101114). Dordrecht, Kluwer.

Megalakaki, O. \& Tiberghien, A. (1995). Learning modeling through the successive resolution of problems. Actes du colloque: European Conference on Cognitive Science (ECCS' 95) Saint Malo. 4-7 April. 91-98.

Nersessian, N.J. (1999). Model-based reasoning in conceptual change. In L. Magnani, N.J. Nersessian \& P. Thagard (Eds.), Models are used to represent reality, (pp. 5-22), New York: Kluwer Academic/Plenum Publishers.

Ogborn, J. (1998). Cognitive development and qualitative modelling. Journal of Computer Assisted Learning, 14, 292-307.

Perkins, D.N. (1986). Knowledge as Design. Hillsdale, NJ: Lawrence Erlbaum Associates.

Posner, G.J., Strike, K.A., Hewson, P.W., \& Gertzog, W.A. (1982). Accommodation of a scientific conception: Toward a theory of conceptual change. Science Education, 66, 211227.

Shipstone, D.M. (1988). Pupils' understanding of simple electrical circuits. Physics education, 23.

Solomon, J. (1992). Getting to know about energy-in school and society. London: The Falmer Press.

Tiberghien, A. \& Megalakaki, O. (1995). Characterization of a modeling activity for a first qualitative approach to the concept of energy. European Journal of Psychology of Education, 4, 369-383.

Tiberghien, A. (1994). Modeling as a basis for analyzing teaching-learning situations. Learning and Instruction, 1, 71 - 87.

Torrano, F. y Fernández, M.C. (2004). Self-Regulated Learning: Current and Future Directions. Electronic Journal of Research in Educational Psychology, 2 (1), 1-34. 
Vosniadou, S. \& Brewer, W.F. (1994). Mental Meaning of the day/night cycle. Cognitive Science, 18, 123-183.

Vosniadou, S. (2002). On the nature of naive physics. In M. Limon \& L. Mason (Eds.), "Reconsidering conceptual change: Issues in theory and practice" (pp. 61-76). Dordrecht: Kluwer.

Yu, Q. (2002). Model-based reasoning and similarity in the world. In L. Magnani \& N.J. Nersessian (Eds.), Model-based reasoning: Science, technology, and values. New York: Kluwer Academic/Plenum Publishers. 


\section{APPENDIX}

Appendix 1. Text introducing students to a basic theoretical model of energy.

Energy can be characterised by:

Its properties:

- Storage

The reservoir stores energy

- Transformation

The transformer transforms energy

- Transfer

Between a reservoir and a transformer, between two reservoirs, or between two transformers, there is a transfer of energy from one system to another:

- By work,

Energy transfer takes place in the form of mechanical work when an object moves during an interaction, and in the form of electrical work when there is an electric current (flow of electric charge)

- By heat,

- By radiation.

Energy can also be characterised by: The law of conservation of energy Energy is conserved whatever the nature of its transformation, transfer or storage.
To build an energy chain

the following symbols must be used:

res. for reservoir

$\longrightarrow$ for transfer

tr. for transformer

indicating:

- in each rectangle or oval, the corresponding element in the experiment;

- under each arrow, the mode of transfer;

putting

- an arrow next to the mode of transfer.

The following rules must be followed:

- A complete energy chain starts and ends with a reservoir;

- The initial reservoir is different from the final reservoir. 
Appendix 2. Extract of a dialogue between two students

\begin{tabular}{|c|c|c|c|c|}
\hline $\operatorname{Ref}$ & Pair & Oral production & Gesture & Cognitive process \\
\hline 144 & S. & $\begin{array}{l}\text { "No, because, in fact, look } \\
\text { over there }{ }^{1} \text { that stores en- } \\
\text { ergy" }\end{array}$ & $\begin{array}{l}1 \text { Points to the motor and } \\
\text { looks round }\end{array}$ & $\begin{array}{l}\text { Ref. 144-152 } \\
\text { Similarity of structure }\end{array}$ \\
\hline 145 & M. & "What does it store?" & & \\
\hline 146 & S. & "Look here" & & \\
\hline 147 & M. & "Yeah" & & \\
\hline 148 & S. & $\begin{array}{l}\text { "After that, it comes out } \\
\text { there" }\end{array}$ & $\begin{array}{l}\text { Takes the string attached } \\
\text { to the object in his hand, } \\
\text { then the object itself }\end{array}$ & \\
\hline 149 & M. & "No, that's a transfer ${ }^{1 "}$ & ${ }^{1}$ Wire & $\begin{array}{l}\text { Ref. } 149 \\
\text { Matching: Wire-Transfer }\end{array}$ \\
\hline 150 & S. & $\begin{array}{l}\text { "Yes, but there, that would } \\
\text { be a reservoir } 1 " \text { / }\end{array}$ & ${ }^{1}$ Touches the motor & $\begin{array}{l}\text { Ref. 150 Matching: } \\
\text { Motor-Reservoir }\end{array}$ \\
\hline 151 & M. & "The reservoir" & & \\
\hline 152 & S. & $\begin{array}{l}\text { "Stores energy and to put it } \\
\text { there } 1 "\end{array}$ & ${ }^{1}$ Object & \\
\hline 153 & M. & $\begin{array}{l}\text { "If not, we can say that this } 1 \\
\text { is a reservoir, this } 2 \text { is a } \\
\text { transformer, the bulb }{ }^{3} \text { is } \\
\text { another transformer. Do you } \\
\text { understand?" }\end{array}$ & $\begin{array}{l}1 \text { Takes the object in his } \\
\text { hand } \\
2 \text { Points to the motor } \\
3 \text { Points to the bulb }\end{array}$ & $\begin{array}{l}\text { Ref. 153-157 } \\
\text { Similarity of structure }\end{array}$ \\
\hline 154 & S. & "A reservoir?" & & \\
\hline 155 & M. & $\begin{array}{l}\text { "Well yes, it's a reservoir } \\
\text { because it falls, in fact, it's a } \\
\text { quantity" }\end{array}$ & $\begin{array}{l}\text { M looks at } S \text { and explains } \\
\text { to } S \text {, touching the wire and } \\
\text { the object }\end{array}$ & $\begin{array}{l}\text { Ref.155 } \\
\text { Intermediate interpretation }\end{array}$ \\
\hline 156 & S. & $\begin{array}{l}\text { "But the force didn't exist } \\
\text { before, so it's a reservoir of } \\
\text { nothing" }\end{array}$ & & $\begin{array}{l}\text { Ref. } 156 \\
\text { Intermediate interpretation }\end{array}$ \\
\hline 157 & M. & $\begin{array}{l}\text { "Yes there is, you can see } \\
\text { how the reservoir fills up. } \\
\text { You just have to raise it. } \\
\text { When the object goes up, } \\
\text { the reservoir fills up!" }\end{array}$ & $\begin{array}{l}{ }^{1} \text { Laughs and lifts the ob- } \\
\text { ject up }\end{array}$ & $\begin{array}{l}\text { Ref. } 157 \\
\text { Intermediate interpretation }\end{array}$ \\
\hline
\end{tabular}

